\title{
A Contingent Relationship Between Risk and Return: Toward A Behavioral Model of Decision Making
}

\author{
Ananda Mukherji \\ Texas A \& M International University \\ Ashay B. Desai \\ The University of Wisconsin Oshkosh \\ Peter Wright \\ The University of Memphis
}

\begin{abstract}
Different researchers have conceptualized the risk-return relationship as being positive, negative, or curvilinear. This paper proposes a framework where different theoretical approaches can be mapped onto a two-dimensional risk-return space in order to reconcile them. Rather than a single and fixed reference point, we propose that there are two additional reference points. Furthermore, we present a polynomial risk-return relationship that suggests a negative risk-return relationship below and above the failure and success reference points, and a positive relationship in between the two points. Practitioner as well as research implications are discussed.
\end{abstract}

\section{Introduction}

The study of risk and return continues to be an area of vital importance for researchers; however, the theorizing and empirical findings in this area continue to present a series of problems. The risk-return relationship has been presented in the literature in two distinct ways. One is the discussion on whether the relationship between risk and return is positive, negative, or curvilinear (Fiegenbaum, Hart, \& Schendel, 1996). The second involves empirical anomalies that researchers are confronted with when examining the numerous studies in this area (for a brief review, see Gooding, Goel, \& Wiseman, 1996; Wiseman \& Catanach, 1997). There have been relatively few explanations that have satisfactorily reconciled these differences. The purpose of writing this paper is to suggest that the differently theorized risk and return relationships, as well as the contradictory empirical findings can be largely explained using our proposed model. The existing differences in theories and the contradictory empirical findings can be explained by suggesting that different groups of researchers may have addressed specific domains of the risk-return relationship. Within the confines of a particular domain in the risk-return relationship, each theoretical approach and its associated empirical findings may appear consistent; however, as different theoretical approaches are somewhat narrow, no one approach is possibly sufficient to explain the contradictions that arise when domains are enlarged, associated assumptions changed, or situational variables are introduced. 
In developing our model, we borrow from the behavioral theory of the firm (Cyert \& March, 1963; March, 1994; Bacharach, Bamberger, \& Sonnenstuhl, 1996), which incorporates the role of certain situational or contextual variables in the decision making process. Wolf (1977) has mentioned that internal and external environmental changes force firms to realign their strategies. Before presenting our proposed model, we briefly examine certain risk-related terms that will be used in this paper. These include the definition of risk, as well as the two important managerial behaviors that are integral to decision making -- risk seeking and risk averse behaviors. Next, we briefly examine the different theoretical approaches in the risk-return relationship, and review the empirical evidence, which taken together present contradictions. We examine three key situational variables -- slack, aspirations, and performance -- all of which impact managerial decision making (Cyert \& March, 1963; March, 1994). Once these situational variables are incorporated into our model, the different theoretical approaches as well as the empirical anomalies are better explained. Next we present two frameworks (Figures 1 and 2) that explain the range and space within which managerial decision making takes place. We then present our proposed model that suggests a polynomial risk-return relationship. A polynomial relationship does help reconcile the different theoretical approaches in the risk-return relationship and it also addresses some of the empirical anomalies. After presenting the model, we suggest a number of propositions that examine the risk-return relationship.

\section{Defining Managerial Risk Behaviors}

\section{Risk, Risk Seeking, and Risk Aversion}

\section{$\underline{\text { Risk }}$}

The role of uncertainty and the lack of knowledge about the specific consequences of an action are important components of risk-related decision-making. The most commonly considered situations involving uncertainty are where the precise consequences are uncertain but their probabilities are known (March, 1994). In March's (1994) view, the most conventional approach to predicting decision making is to assume a decision maker will choose the alternative that maximizes expected value; that is, the alternative that would produce the best outcome if a particular choice were to be made many times. According to Mullen and Roth, "risk is the existence of states beyond the decision maker's control that affect the outcome of his or her choices. The degree of risk is a function of the size of the potential loss and the probability of that loss" (1991:191). For decision makers, the notion of risk is closely associated with the concept of return, and variations around a return. When considering risk, a decision is seen as a joint function of the expected value (or mean) and the riskiness (the variance) of the probability distribution over outcomes conditional on choice of a particular alternative (March, 1994: 7).

In an essay on decision making, March (1994) mentions that among students of risk and decision making, there are two broad schools of theorists. One is the school of 
formal theorists and the other is the behavioral school of decision making. The formal theorists conceptualize risk as a label for the residual variance in a theory of rational choice. Here the approach is to assume that risk preference accounts for any deviation in observed behavior from the behavior that would be observed if decision makers had utilities that were linear with money and made decisions by maximizing expected monetary value. Behavioral theorists of decision making, on the other hand, attempt to examine the behavioral and cognitive processes that precede decision making. We take a behavioral approach in this paper and examine how the configuration of certain situational variables affects choice and risky behaviors.

\section{$\underline{\text { Risk Seeking }}$}

Risk seekers will take choices that involve greater potential loss and/or a higher probability of a loss, and at the evaluation stage, risk seekers tend to take information at face value (Mullen \& Roth, 1991). Risk seekers typically underestimate risk in the sense that they tend to overestimate gains and underestimate losses. At the earliest stage of problem recognition, risk seekers perceive risks as being lower than risk averters. Risk seekers focus more on the opportunities for gain or the potential for gain (Tiegen \& Brun, 1997), or they may so behave on account of personality dispositions. Lopes (1987), for example, has suggested a typology based on gain-dominated behavior versus habitual loss-focused behavior, distinguishing between risk seeking potentialmindedness on the one hand, versus risk averse security-mindedness on the other. Apart from managerial behaviors, situational characteristics also determine risk-related decision making. March and Shapira (1992) have suggested that people become more aspiration-oriented when they focus on positive goal attainment, otherwise their perceptions and behaviors may be more survival-oriented focusing on losses when their resources are threatened by depletion.

\section{Risk Aversion}

Risk averters are more attentive to monitor or track the consequences of their decisions compared to risk seekers, and as a consequence, risk averters tend to demand more information on probabilities, adopting worst-case scenarios (Mullen \& Roth, 1991). Risk averters typically overestimate risk in that they tend to overestimate losses and underestimate gains. At the earliest stage of problem recognition, risk averters perceive risks as being higher than risk seekers. Moreover, risk averters focus more on the likelihood of loss or the potential for loss on account of personality dispositions (Tiegen \& Brun, 1997), or may have a habitual disposition for loss-focused behaviors that result in risk averse security-mindedness (Lopes, 1987), or may be risk averse and survivaloriented due to resources threatened by depletion (March \& Shapira, 1992). 


\title{
The Relationship Between Risk and Return
}

\author{
$\underline{\text { Positive, Negative, and Curvilinear Relationships }}$
}

\section{Positive Relationship}

An important foundation of the risk-return relationship is the notion that managers are generally risk averse. This approach is well accepted in formalist theories of decision making that are based on notions of individual rationality and maximization of utility. Agency theory, a formalist theory, is based on assumptions of rational behavior and economic utilitarianism (Ross, 1973), and assumes a linear positive relationship between risk and return. Risk behavior has been associated with assumptions of rational behavior, outcome weighing, and utility maximization. Financial theory posits that risk averse behavior is manifest when low risk is associated with low return, as well as when high risk is rewarded by high return (Fisher \& Hall, 1969). This risk averse outlook also assumes that for each strategic alternative, firms and managers will choose that alternative which maximizes utility (Schoemaker, 1982). Aaker and Jacobson (1987) found support for a positive association between performance and both systematic and unsystematic risk, when risk was defined using accounting data. A number of other studies have also found support for a positive risk-return relationship (Bettis, 1981).

\section{$\underline{\text { Negative Relationship }}$}

It was, however, the work of Bowman $(1980,1982)$ and the 'Bowman's Paradox' which suggested that his findings were at considerable variance with classical finance theory. Bowman (1980) found a distinct and significant negative relationship between risk and return. Examining a large sample of firms from 85 industries, Bowman found a negative relationship between risk and return among firms that were performing well, as well as a negative return between risk and return for firms performing poorly. Bowman's (1980, 1982) interpretations of his findings were that managers may be risk seekers under certain circumstances. Well-managed firms, according to Bowman $(1980,1982)$, appeared to be able to increase their returns and reduce risk simultaneously (suggesting an apparent paradox on account of the negative relationship), and in contradiction with the positive risk-return relationship postulated by the formal theorists. The paradox in the risk-return association, the negative relationship found by Bowman $(1980,1982)$, where there is one cluster of high risk and low return firms (the inferior performers), and another cluster of low risk and high return firms (the superior performers), was also supported by other researchers (Fiegenbaum \& Thomas, 1986; Cool \& Dierickx, 1987).

\section{Curvilinear Relationship}

A third body of research, using Kahneman and Tversky's (1979) prospect theory explanations, found a curvilinear relationship between risk and return. Prospect theory suggests that people outweigh outcomes that are probable compared with outcomes 
that are certain. As a consequence, people prefer sure gains to likely gains, and prefer likely losses to sure losses. The concept of a reference point is central to prospect theory explanations. Many researchers assume that a reference point is typically the industry average or the performance of referent other firms. Performing below or above the reference point affects managers' assessment of risk and consequent risk taking. The major prediction of prospect theory is that managers are both risk seeking and risk averse, depending on whether managers consider themselves to be in the domain of (relative) gains or (relative) losses. A fundamental argument of prospect theory is that managers use reference points in evaluating risky choices, and adopt risk seeking behaviors when operating below the reference point, and risk averse behaviors when operating above the reference point (Kahneman \& Tversky, 1979). There is also considerable research support for a curvilinear relationship (Chang \& Thomas, 1989; Fiegenbaum \& Thomas, 1988; Singh, 1986). Prospect theory explains how the same manager may exhibit different types of risky behaviors that are predicated by relative performance and other feedback. Fiegenbaum et al. (1996) have argued for a linkage between reference points and a firm's strategic realignment.

In addition to these three theoretical approaches -- positive, negative, and curvilinear, there are some intriguing anomalies and contradictions that are worth pointing out. Prospect theory suggests that managers adopt risk seeking behaviors when their expected outcomes from actions are below their reference point, and risk averse behavior when expected outcomes are above their reference point. There are, however, some empirical findings that are contrary to the predictions of prospect theory (Highouse \& Yüce, 1996). Studies in decision making have found that past success increases the willingness to take risks (Osborn \& Jackson, 1988; Thaler \& Johnson, 1990), or that past failures lead to rigidity and risk averse behavior (Staw, Sanderlands, \& Dutton, 1981). There exists a range of risk-related behaviors to which there is no clear and composite theory or unifying explanation. Our aim is to present a model where a range of behaviors and risk preferences can be explained by examining various situational variables. We examine the relative position with regard to a firm's performance from certain reference points, and how these positions may affect managerial decision making.

Situational Variables

Slack, Aspirations, and Performance

$\underline{\text { Slack }}$

Organizational slack is a critical situational variable that affects managerial decision making. While there is some disagreement over what precisely constitutes slack (Wiseman \& Catanach, 1997), it is widely used in risk related research. Building on the work of Cyert and March (1963), Bourgeois suggests that slack is something that is available, recoverable or potential, and defines it as, "that cushion of actual or potential resources which allows an organization to adapt successfully to internal pressures for change in policy, as well as, initiate changes in strategy with respect to the external 
environment" $(1981,30)$. Slack also includes undiscovered and unexploited technological, marketing, and cost reduction opportunities, as well as, undiscovered and exploited strategies (March, 1994). The resulting cushion of unexploited opportunities and undiscovered economies, the difference between a decision maker's realized achievement and potential achievement, is slack (March, 1994).

A number of researchers have proposed a behavioral view of slack, in that managerial risk taking has a fully convex relationship between slack and risk taking (Wiseman \& Catanach, 1997). The behavioral view (Cyert \& March, 1963; March, 1994; Bacharach, Bamberger, \& Sonnenstuhl, 1996) suggests that managers accept greater risk when faced with both high and low levels of slack. These researchers compellingly argue that both high and low levels of slack increase risk taking. At extremely low levels of slack, the firm must make risky decisions to remain solvent, while at high levels of slack, the firm can afford to take risks knowing that it has sufficient resources so that failures will be relatively harmless. Thus, far from there being a linear relationship between the level of slack and risk taking, we follow the behavioral view that the relationship is a fully convex one.

\section{$\underline{\text { Aspirations }}$}

Aspirations are desires or goals that managers have regarding the level of performance they wish to achieve. Performance, in turn, is closely associated with aspirations, and aspirations may possibly change over time. Past performance and comparison to the performance of referent other firms will strongly influence aspiration levels (Cyert \& March, 1963; March, 1994; March \& Simon, 1958). Aspirations are also considered to be a function of previous aspiration levels and past performance (Cyert \& March, 1963; Levinthal \& March, 1981). Results that exceed aspirations are treated as "successes," reinforcing managers' inclination to maintain the rules on which the actions were based, while "failures" occur when results fall short of aspirations, encouraging managers to change the rules on which the actions were based (March, 1994, 88). The learning process, according to March (1994), depends critically not only on the association between outcomes and actions (and the related decision rules), but also on the aspirations of such outcomes. The relationship between risk taking and aspiration levels is complicated, but would depend considerably on whether "decision makers focus attention on their hopes (organized around their aspiration level) or on their fears (organized around their extinction level)" (March, 1994: 43). Further, according to March (1994), satisficing theories predict that as long as performance exceeds aspirations, search for new alternatives is modest, slack accumulates, and aspirations increase. When performance falls below aspirations, search is stimulated, slack decreases, and aspirations decrease.

\section{Performance}

The relationship between performance and risk continues to be an intriguing one. According to March (1994), the social construction of success and failure may mirror the social structure of an organization or society, with different groups defining the same 
outcomes differently. When managers find themselves well above a particular performance target, they tend to take greater risk on the assumption that in that position, they have little chance of failing, and partly because of inattention as a result of considerable slack (March, 1994). March (1994) also uses the same argument to suggest that as managers fall farther and farther below their targets, they tend to take bigger and bigger risks to increase the chance of achieving their targets. March and Shapira (1992) have also suggested that managers become more aspiration-oriented when they focus on positive goal attainment. On the other hand, when faced with resource depletion, managers' perceptions become more survival oriented. Like slack and risk taking, performance and risk taking also bear a fully convex relationship.

Assessment of performance has an important influence on decision making and managerial risk taking. Numerous studies have indicated that the outcome (success or failure of past actions) of an initial decision to commit resources to a course of action frequently influences subsequent decisions (Bateman \& Zeithaml, 1989; Fox \& Staw, 1979; Staw \& Ross, 1978) on whether to continue, increase, or decrease commitment. Staw's (1981) finding about escalating commitment to a losing course of action complements social cognition theories that suggest that threatening events lead to risky and adaptive behaviors. Staw (1981) also suggested that a motivation to self-justify or to prove the rationality of an earlier decision may explain escalating commitment. Past performance is an important input to managers in their decision making processes.

\section{Managerial Behaviors at Different Reference Points}

There is some support for the idea that, rather than there being a single fixed reference point like an industry average performance, there is a strong likelihood of the existence of multiple reference points (Gooding et al., 1992, Gooding, Goel, \& Wiseman, 1996). Other researchers, who argue for variable reference points, have raised persuasive arguments challenging a single fixed reference point (March, 1988; March \& Shapira, 1987; March \& Shapira, 1992). Their arguments, built around the behavioral theory of the firm (Cyert \& March, 1963; March, 1994), suggest that reference points are linked to the aspirations and expectations of managers. Aspirations and expectations are, in turn, tied to a firm's performance history and comparison to the performance of others (March \& Simon, 1958; Cyert \& March, 1963), and are also a function of previous aspiration levels and previous performance levels (Wiseman \& Bromiley, 1996). March (1994) has also argued convincingly that managers are likely to increase risk taking when operating either very far below or very far above their performance reference points.

There has been considerable thought about how managers perceive their performance, and how this affects their decision making. The perceptions managers have and the search routines they undergo are based on comparison of achievement to targets which are aspiration levels for important dimensions (March (1994). Failure increases search and success decreases it, and search continues as long as achievement is below the target and ends when the target is exceeded (March, 1994). Beyond this, while the literature and empirical work is still in a developmental stage, scholars have theorized and empirically tested for variable reference points (Gooding et al., 1996). Based on 
Prospect Theory (Kahneman \& Tversky, 1979), it is argued that managers whose firms experience performance declines evoke a loss context and seek out riskier alternatives, while those who experience improved performance evoke a gain context and choose less risky alternatives (Gooding et al., 1996, p. 332).

Theorizing and testing for multiple or variable reference points is central to the work of Goodings et al. (1996). They suggest that a gain-loss reference point greater than median industry performance could explain some previously reported anomalies, and theorize that if the reference point is elevated then managers become risk averse. Goodings et al. (1996) also suggest that firms which experience substantial or continuous losses may use a second reference evoking a different decision context, and they term this point the survival reference point -- which reflects a comparison between the form's current performance and some level of hazard or ruin.

Researchers have formulated an aspiration or success level that is past performance multiplied by an adjustment factor. For example, for firms with performance levels above the industry mean, aspiration levels are computed by Bromiley (1991) by multiplying past performance by 1.05. Similar adjustment factors have been used by researchers (Lant \& Montgomery, 1987) in examining risk, decision making, and performance, and Bromiley (1991) has constructed other adjustment factors like 1.25 and 1.50 .

Indeed the issue as discussed earlier in this paper is how managers handle failure. One view is the "threat rigidity" hypothesis presented by Staw, Sanderlands, and Dutton (1981). This view is contrasted by March (1994) who suggests that failure induces search, and decision makers threatened with failure focus on cutting costs, produce better, and market more effectively.

While the theory with regard to multiple reference points is still underdeveloped in being able to provide an accurate estimation of failure and success reference points, the preponderance of the evidence suggests that such multiple points are likely to exist. The challenge for researchers is to refine the theory further and look for ways to empirically test for the existence of these multiple reference points.

Bromiley (1991) and Gooding et al., (1992, 1996), among others, have argued for multiple reference points, including that of a success reference point. Their argument is that firms with above average performance use their current performance plus some growth factor as a standard for success. Similarly, Bromiley (1991) argues that those firms operating below the industry average aspire to average performance. The question we ask is, which kind of below average firms aspire to improve their performance toward an industry average? Are those firms below, though near, the industry average more likely to take significant action? Or are those firms that are at or below some failure reference point more likely to take significant action? We argue it is more likely that firms who take significant action are the ones at or below their failure reference point. Similarly, we ask, which kind of above average firms aspire to take bold and risky actions? Are those firms above, though near the industry average, more likely 
to take bold action? Or are those firms that are way above their success reference point more likely to take bold and risky action? We again argue that firms taking bold and risky action are the ones at or above their success reference point. Our reasoning for the risky action of firms that are at or far below their failure reference point, or are at or far above their success reference point is based on the convex relationship among slack, aspirations, and performance (Cyert \& March, 1963; March, 1994; Wiseman \& Catanach, 1997). In the rest of this section, through the use of a diagram (Figure 1), we explore why firms make risky decisions.

\section{Figure 1}

\section{Managerial perceptions at different reference points}

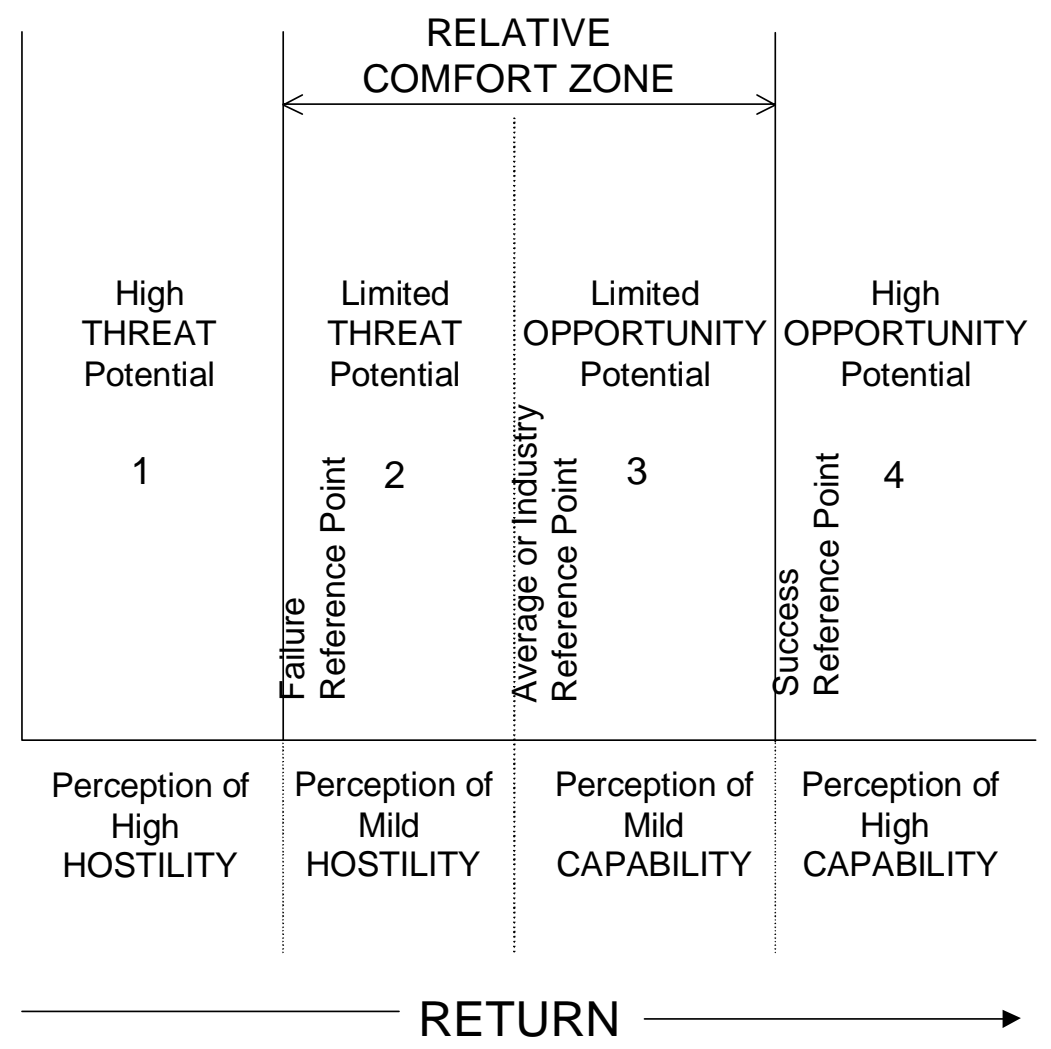

As Figure 1 suggests, that firms when operating around the industry or average reference point (in this paper we do not indicate what the reference specifically alludes to, nor do we specify how it is computed), the degree of perceived threat or perceived opportunity is limited. When operating below but near the reference point (zone 2 in Figure 1) the threat perception to managers is limited. Similarly, when operating above but near the average reference point (zone 3), not only is there a perception of limited opportunity, but also a perception that the organization's capabilities are about adequate. We term this region as the "relative comfort zone," and argue that when faced with the perception that losses or gains are limited, managers are likely to be risk averse. As a consequence, managers would prefer to make improvements 
incrementally and cautiously. Managers will be concerned about what can go wrong, and will be inclined to maintain the status quo and not stray too far from their relative comfort zone.

Contrast this with firms operating outside of its relative comfort zone at a considerable distance from the average or industry reference point. Here firms are operating at or below their failure reference point (zone 1). Here firms are approaching a ruinous state from which no recovery may be possible. Falling below a failure or survival reference point (Gooding et al., 1996) may galvanize managers to take action and risky decisions to avert insolvency or liquidation. There is an increasingly high threat potential for managers to grapple with, and the environment is likely to be perceived as being very hostile. Managers are likely to look for ways to counteract the current poor form, and address the issues that have contributed to the current adverse conditions. Managers are likely to make strenuous efforts to get over the failure reference point and place themselves in the relative comfort zone, even if their efforts place their firm below the industry reference point. Consequently, managers are likely to take some action to alleviate their adverse situation by moving their performance level to at least above the failure reference point.

Finally, we examine the case of being substantially above the reference point; where firms are operating at or above their success reference points (zone 4). Here managers may feel that the opportunity potential is high, and they may perceive a high degree of organizational capability. If managers feel that they have crossed beyond a success reference point, they may have a greater tendency to take risks by exploring new concepts, investing more aggressively in R\&D, and being receptive to new markets and new products. Managers will be concerned with the promise of what can be gained, and would not like to miss out on possible opportunities. In such situations, when operating at or above the success reference point, the probability of undertaking risky behaviors is likely to increase. The explanations presented by March (1994), and March and Shapira (1992) further reinforce our arguments supporting risky behaviors by managers when facing extreme conditions. Jones and Kashlak (2001) also suggest that firms that are extremely high or low relative to their reference point seek a higher degree of risk while firms moving towards their reference points decrease their risk, and firms at their reference point are risk averse.

\section{A Polynomial Risk-Return Relationship}

\section{Relative Performance and Risk}

Based on the arguments made so far, we suggest that in addition to an average or industry reference point, there exists a failure reference point below the average, and a success reference point above the average. We also suggest that decision making and risky behaviors will vary substantially and would depend on which region the firm is operating in. Based on our reasoning, a polynomial risk-return relationship could explain not only the different theoretical approaches, but also much of the anomalies and contradictions encountered in empirical studies. Figure 2 presents a polynomial risk- 
relationship model.

\section{Figure 2}

\section{A polynomial risk-return relationship model}

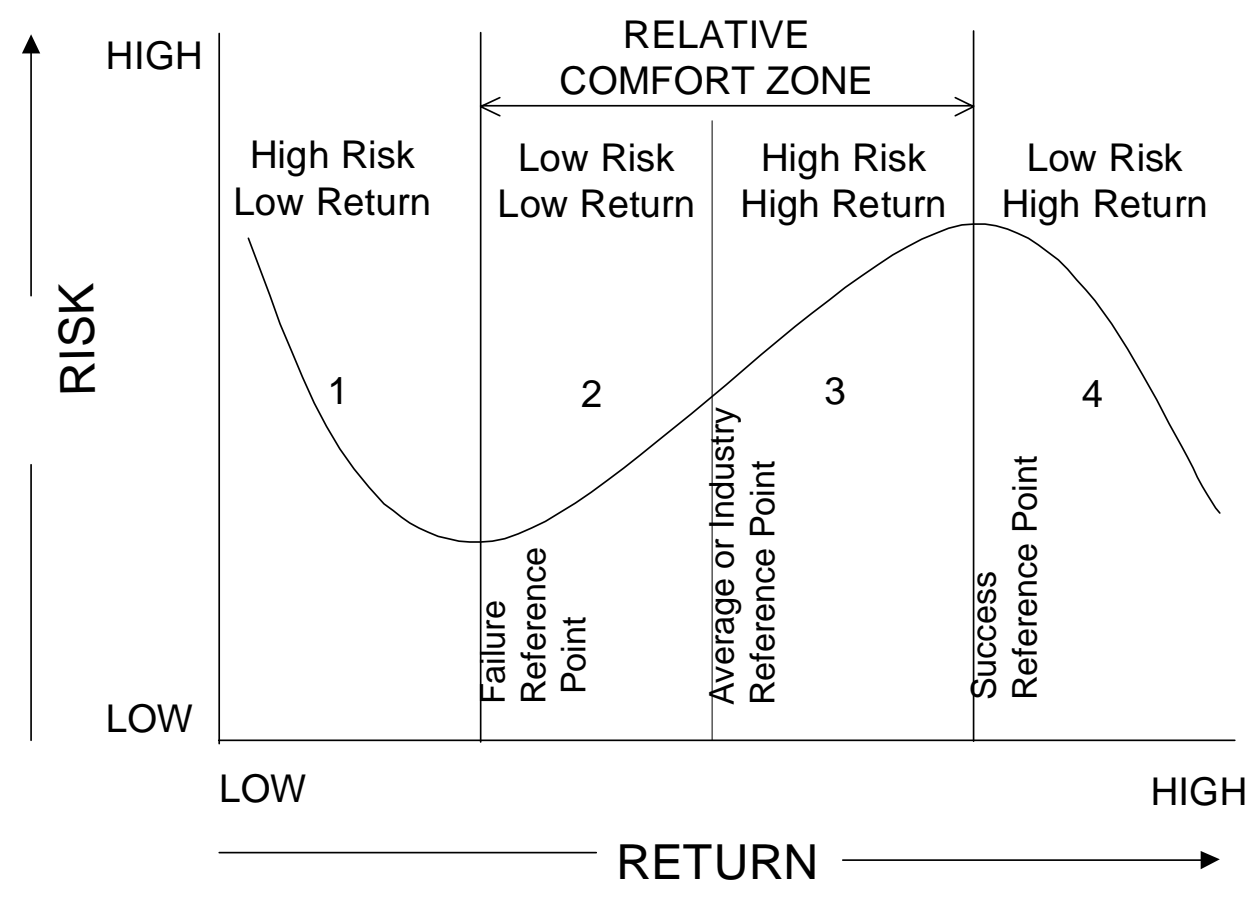

Figure 2, like Figure1, consists four zones. In zone 1, when operating at or below the failure reference point, the situation is one of high risk and low return. In order to combat this adverse situation and to avoid bankruptcy, managers will attempt to lower risk from the current high levels, and aspire to move toward average performance (the average or industry reference point). In short, managers in a high risk-low return situation will attempt to move to a low risk-low return situation, and exhibit risk seeking behaviors. They may, for example, start selling off productive assets to generate cash to pay debtors, an action they might not have considered if performance levels had been better. Based on this reasoning, we present the following proposition with regard to managers in zone 1:

Proposition 1: Managers of firms operating below their failure reference point will have a negative relationship between risk and return, and will exhibit risk seeking behaviors.

When in zone 2 or in zone 3, managers will be in their relative comfort zone and performance will be hovering around -- either slightly above or slightly below -- the average or industry reference point. As discussed earlier, the relative comfort zone is 
located between the success and failure reference points. In order to not upset the status quo, and for the reasons discussed in the previous section, managers are likely to be risk averse. Managers in zone 2, which is characterized by a low risk-low return combination, would prefer to exercise the choice of increasing risk and obtain return in a proportionate manner. If risk increases disproportionately, they risk the possibility of slipping into a situation of high risk-low return (zone 1). To avoid that, managers may choose the option of attempting to move to zone 3 where there is a proportionate relationship between risk and return. Managers also have the choice of attempting to move from zone 2 to zone 4 , but the probability of boosting return without increasing risk is low. This is because implementing a strategy of simultaneously increasing return and decreasing risk is extremely difficult. Most managers would prefer moving to zone 4 by going through zone 3 in an incremental fashion, rather than in a more drastic manner. Consequently, for operations and performance within the relative comfort zone, we propose the following:

Proposition 2: Managers of firms operating within their relative comfort zone will have a positive relationship between risk and return, and will exhibit risk averse behaviors.

In zone 4, which is for firms doing very well, and operating at or above their success reference point, there is little to lose by taking risky or bold decisions. Managers of such firms believe they have enough resources and slack to follow through and succeed (or even fail) with their decisions. We would argue that firms in zone 4 have managed to master the risk-return dimension when compared to firms in the other three zones. In zone 4, managers are faced with the advantage of low risk and high return, something that the managers in the other three zones aspire for. Coupled with low risk and high return, such firms which are performing at extremely high levels, are likely to have considerable slack, and perceive their own organizational capabilities to be of a high order. Managers in zone 4 are also likely to feel that their considerable resources can offset adverse outcomes from their risky decisions, and that their actions would not negatively affect their firms even if the decisions did not work as anticipated. Given these, we predict that zone 4 managers are likely to take bold and increasingly risky decisions. Hence we propose the following:

Proposition 3: Managers of firms operating above their success reference point will have a negative relationship between risk and return, and will exhibit risk seeking behaviors.

\section{A Polynomial Risk-return Relationship}

Here we present a polynomial risk-return relationship where the general nature of the analytical model would be that of a non-linear or non-additive model. This can usually be understood in the context of multiple regression analysis by using powered vectors of variables (Pedhazur, 1982). In the case of a single independent variable it would take the following form:

$$
Y=a-b_{1} X+b_{2} X^{2}-b_{3} X^{3}
$$


We ignore the intercept term (the constant [a]) in the model and proceed to analyze the regression equation. The dependent variable $(Y)$ is risk, and the independent variable $(X)$ is return. The first term $\left[-b_{1} X\right]$ corresponds to the risk-return relationship in zone 1 and is indicative of risk seeking behavior. The sign indicates a negative sloped riskreturn relationship below the failure reference point. The second term $\left[+b_{2} X^{2}\right]$ indicates the first reversal that takes place around the failure reference point, and now the riskreturn relationship is positive. The expected sign is positive and there is a positive slope in zones 2 and 3 , the relative comfort zone, which is the region between the failure reference point and the success reference point. The third term $\left[-b_{3} X^{3}\right]$ indicates a second reversal, which takes place around the success reference point. Here again the slope is negative indicative of an inverse relationship between risk and return. The negative sign in zone 4 also indicates risk seeking behavior. Using the power polynomial regression equation given above, an S-shaped curvilinear relationship between risk and return (Figure 2) with two inflection points can be established. Such a curve would have a negative parameter estimate for the first and third (cubed) terms, and a positive parameter estimate for the second (squared) term.

Thus, we would not only expect a cuboid equation of the form described, we would also expect the signs to be in the directions as indicated. In support of the expected polynomial relationship between risk and return, we present additional propositions. In establishing the negatively sloped risk-return relationship, and also indicative of risk seeking behavior in zone 1, we propose the following three propositions that, in effect, complement the first three that were proposed earlier.

In support of the negatively sloped risk-return relationship, and also indicative of risk seeking behavior in zone 1, we propose:

Proposition 4: Risk exhibits a negative association with return in zone 1.

In support of the positively sloped risk-return relationship, and also indicative of risk averse behavior in zone 2 and zone 3 (the relative comfort zone), we propose:

Proposition 5: Risk exhibits a positive association with return squared in zones 2 and 3.

In support of the negatively sloped risk-return relationship, and also indicative of risk seeking behavior in zone 4, we propose:

Proposition 6: Risk exhibits a negative association with return cubed in zone 4.

\section{Discussion, Practical Implications and Conclusion}

Our objective in this paper is to address a number of unresolved issues in the risk-return relationship. The first is to highlight the fact that there are a number of distinct, though contradictory approaches in the way risk and return have been theorized. As a result, empirical research has produced contradictory results. There has been limited theoretical and empirical work to reconcile these different approaches and 
disagreements. We suggest, based on well-accepted behavioral theories, that managers' decisions are affected by situational variables, and we have incorporated slack, aspirations, and performance in our model. This research is also in line with Chakravarthy's (1997) suggestions for strategy researchers to focus more on turbulent environments and move away from focusing on stable environments.

Based on the reasoning we have provided, and supported by a number of other researchers, we have made the case for two additional reference points, apart from the average or industry reference point. These are a failure reference point, and a success reference point. We suggest that firms operating below their failure reference point are likely to be risk seeking in order to overcome their current problems and move toward the industry average. For firms above the success reference point, managers are again likely to be risk seeking, though for entirely different reasons. Here risk seeking behaviors take place on account of perceptions of high organizational slack, and high organizational capabilities and excess slack. For firms operating between their failure reference point and their success reference point, essentially those operating in the relative comfort zone, managers are likely to be risk averse.

We have suggested that, as a matter of choice, managers would prefer to be in a low risk - high return environment. In any other situation, managers will be facing either unacceptable levels of risk or low levels of return or both. There are two major factors that impact managerial thinking in assessing firm performance. The first is a level of return above which the firm should operate, and the second is a level of risk below which a firm should operate. In other words, given a level of risk, what is an acceptable rate of return? Here, the effort would be to manage risk and increase returns. The second is, given a level of return, what is an acceptable level of risk? Here, the effort would be to manage return and decrease risk. We believe our paper addresses a number of important issues in the risk-return relationship, and we believe these propositions can be refined and empirically tested. Our explanation conveys a revised understanding of existing risk seeking and risk averse behavior arguments. The theoretical reasoning offered here advances understanding of organizational risk taking by reconciling and refining prominent models and can be applied to contemporary managerial thinking.

From the shareholders' perspective, companies that continue to reinvent their business model, revise their growth targets upwards, and find ways to apply their already successful strategies to newer markets are considered to be worth investing in. Modifying risk taking by shifting internal reference points may reflect managers taking actions favoring shareholders. Behavioral decision theory advances educating managers and instilling decision processes designed to adjust risk taking. Agency theory recommends the use of monitoring and compensation systems to bring managerial risk taking in line with the interests of shareholders. Our approach can be managerially useful to understand how to go about instigating the necessary changes to achieve the changing reference point arrangement. 
Using the common elements of a rational-economic strategy perspective and a cognitive-political organizational behavioral perspective (Bacharach, Bamberger, \& Sonnenstuhl, 1996), we contend that managers will shift their foci of attention from risk averse to risk taking (movement from one zone to the other) depending on their corporate benchmarks. Creating the peer organizations or aspiration-organizations will affect the internal reference points thereby creating a new sense of urgency regardless of the traditional benchmarks such as industry average. Such thinking can alter input intensity along the desired dimension thereby improving organizational performance. For example, firms could increase risk through R\&D investment if the attention is shifted from their current industry to firm level strategy by shifting the success reference point downwards. Focus on innovation (for example) can thus be encouraged by changing failure or success reference points thus altering the width of the comfort zone.

By theorizing how companies establish organization policies and practices on the basis of comparisons with internal targets (based on aspiration, slack and prior performance), our explanation provides a desired connection between strategy and implementation and practice at sub-organizational levels. Managers adopt different risks postures when presented with newer structure of reference points, suggesting a more complex picture of risk than has emerged from prior risk-return research.

It is important to mention here that risk related studies usually have a narrow definition of risk primarily for measurement reasons. While business risk can include loss of market share, risk of product failure, risk of market failure, bankruptcy, etc., most researchers believe that a given relationship between return (measured as some quantifiable item of profit) and risk (measured at the variation about the mean of the profit measure) is an adequate measure of relationship.

One of the difficulties in theorizing and testing the risk-return relationship is that of anthromorphism. While we theorize about the human cognitive process, we end up testing firms (Sinha, 1994). In short, we examine the historical behavior of firms and treat them as a representative measure of managerial cognition. In other words, we use various theories at the firm level and treat them as proxies that supposedly measure the domain of individual behaviors. This leap has been justified by many, including Bowman (1982), who mentioned that treating a company as an individual is a kind of anthromorphism that apparently is quite common in political science literature as well as in the literature of economics theory. As researchers, we should be cautious about making this leap since research has generally concentrated on ex-post analysis of risk, while managers are likely to take into consideration both ex-post as well as ex-ante risk. There is obviously a major difference between analyzing ex-post risk and return using secondary data, versus obtaining ex-ante primary data through simulations, exercises, and expert estimates.

\section{References}

Aaker, A. D., \& Jacobson, R. (1987). The role of risk in explaining differences in profitability. Academy of Management Journal, 30, 277-296. 
Bacharach, S. B., Bamberger P., \& Sonnenstuhl W. J. (1996). The organizational transformation process: The micropolitics of dissonance reduction and the alignment of logics of action. Administrative Science Quarterly, 41(3), 477-507.

Bateman, T. S., \& Zeithaml, P. C. (1989). The psychological context of strategic decisions: A model and convergent experimental findings. Strategic Management Journal, 10, 59-74.

Bettis, R. (1981). Performance differences in related and unrelated diversified firms. Strategic Management Journal, 2 (4), 379-393.

Bowman, H. E. (1980). The risk return paradox for strategic management. Sloan Management Review, 21 (3), 17-31.

Bowman, H. E. (1982). Risk seeking by troubled firms. Sloan Management Review, 23 (4), 33-42.

Bromiley, P. (1991). Testing a causal model of corporate risk taking and performance. Academy of Management Journal, 43, 37-59.

Chakravarthy, B. (1997). A new strategy framework for coping with turbulence. Sloan Management Review, 38, 69-82.

Chang, Y., \& Thomas, H. (1989). The impact of diversification strategy on risk return performance. Strategic Management Journal, 10 (3), 271-284.

Cool, K., \& Dierickx, I. (1987). Negative risk return relationships in business strategy: The case of U.S. pharmaceutical industry, 1963-1982. INSEAD working paper.

Cyert, M. R., \& March, J. (1963). A behavioral theory of the firm. Englewood Cliffs, NJ: Prentice-Hall.

Fiegenbaum, A., \& Thomas, H. (1986). Dynamic and risk measurement perspectives on Bowman's risk-return paradox for strategic management: An empirical study. Strategic Management Journal, 7, 395-407.

Fiegenbaum, A., \& Thomas, H. (1988). Attitudes toward risk and the risk-return paradox: Prospect theory explanations. Academy of Management Journal, 31. 85-106.

Fiegenbaum, A., Hart, S., \& Schendel, D. (1996). Strategic reference point theory. Strategic Management Journal, 17, 219-235.

Fisher, N. I., \& Hall, G. (1969). Risk and corporate rates of return, quarterly. Journal of Economics, 83, 79-92.

Fox, F., \& Staw, B. M. (1979). The trapped administrator: The effects of job insecurity and policy resistance upon commitment to a course of action. Administrative Science Quarterly, 24, 449-471.

Gooding, R., Goel, S., \& Wiseman, R. (1992). Prospect theory and the risk return relationship: The effect of multiple, elevated and shifted reference points. Paper presented at the Annual Academy of Management Meeting, Las Vegas, NV.

Gooding, R., Goel, S., \& Wiseman, R. (1996). Fixed versus variable reference points in the risk-return relationship. Journal of Economic Behavior and Organization, 29, 331-350.

Highouse, S., \& Yüce, P. (1996). Perspectives, perceptions, and risk-taking behavior. Organization Behavior and Human Decision Processes, 65, 159-167. 
Jones, M. R., \& Kashlak, R. (2001). Socio-regulatory upheaval, reference points and strategic evolution of the cigarette industry. Journal of Business Research, 51, 193-200.

Kahneman, D., \& Tversky, A. (1979). Prospect theory: An analysis of decisions under risk. Econometrica, 47, 263-291.

Lant, T. K. \& D. B. Montgomery. (1987). Learning from strategic success and failure.

Journal of Business Research, 15, 503-517.

Levinthal, D., \& March, J. (1981). A model of adaptive organization search. Journal of Economic Behavior and Organization, 2, 307-333.

Lopes, L. (1987). Between hope and fear: The psychology of risk. Advances in Experimental Social Psychology, 20, 255-295.

March, J. (1988). Variable risk preferences and adaptive aspirations. Journal of Economic Behavior and Organization, 9, 5-24.

March, J. (1994). A primer on decision making: How decisions happen. New York, NY: The Free Press.

March, G. J., \& Simon, H. (1958). Organizations. New York, NY: John Wiley.

March, G. J., \& Shapira, Z. (1987). Managerial perspective on risk and risk taking. Management Science, 33, 1404-1418.

March, G. J., \& Shapira, Z. (1992). Variable risk preferences and the focus of attention. Psychological Review, 99, 172-183.

Mullen, D. J., \& Roth, B. (1991). Decision making: Its logic and practice. Savage, MD: Rowman and Littlefield Publishers, Inc.

Osborn, N. R., \& Jackson, D. (1988). Leaders, riverboat gamblers, or purposeful unintended consequences in the management of complex dangerous technologies. Academy of Management Journal, 31, 924-947.

Pedhazur, E. J. (1982). Multiple regression in behavioral research: Explanation and prediction. (2nd. ed.). New York, NY: Harcourt, Brace, College Publishers.

Ross, S. A. (1973). The economic theory of agency: The principal's problem. American Economic Review, 63, 134-139.

Schoemaker, P. (1982). The expected utility model: Its variants, purpose, evidence, and limitations. Journal of Economic Literature, 20, 529-563.

Singh, J. (1986). Performance, slack, and risk taking in organizational decision making. Academy of Management Journal, 29, 562-585.

Sinha, T. (1994). Prospect theory and the risk return association: Another look. Journal of Economic Behavior and Organization, 24, 225-231.

Staw, M. B. (1981). The escalation of commitment to a course of action. Academy of Management Review, 6, 577-587.

Staw, M. B., \& Ross, J. Commitment to a policy decision: A multi-theoretical perspective. Administrative Science Quarterly, 23, 40-64.

Staw, B, \& Dutton, J. (1981). Threat rigidity effects in organizational behavior: A multilevel analysis. Administrative Science Quarterly, 26, 501-524.

Thaler, H. R., \& Johnson, E. (1990). Gambling with the house money and trying to break even: The effects of prior outcomes on risky choices. Management Science, 36, 643-660. 
Tiegen, H. K., \& Brun, W. (1997). Anticipating the future: Appraising risk and uncertainty. In R. Ranyard, W. R. Crozier, \& O. Svenson (eds) Decision making: Cognitive models and explanations. (pp. 112-127) New York, NY: Routledge.

Tversky, A., \& Kahneman, D. (1981, January 30). The framing of decisions and the psychology of choice. Science, 211, 453-458.

Tversky, A., \& Kahneman, D. (1986). Rational choice and the framing of decisions. Journal of Business, 59 (4), 251.

Wiseman, M. R., \& Catanach, A. (1997). A longitudinal disaggregation of operational risk under changing regulations: Evidence from the savings and loan industry. Academy of Management Journal, 40, 799-830.

Wolf, B. (1977). Industrial diversification and industrialization: Some empirical evidence. Journal of Industrial Economics, 25, 177-191. 